13

\title{
Модель термического окисления кремния
}

\author{
(c) А.В. Фадеев, ${ }^{1}$ Ю.Н. Девятко ${ }^{2}$ \\ ${ }^{1}$ Физико-технологический институт РАН, \\ 117218 Москва, Россия \\ ${ }^{2}$ Национальный исследовательский ядерный университет „МИФИ“, \\ 115409 Москва, Россия \\ e-mail: AlexVFadeev@gmail.com, ydevyatko@mail.ru
}

(Поступило в Редакцию 26 апреля 2018 г. В окончательной редакции 28 сентября 2018 г.)

Миниатюризация и увеличение скорости работы электронных приборов требует получения диэлектрических пленок оксида кремния нанометровой толщины. Для создания таких структур необходимо понимание процесса начального окисления кремния. Предложена теоретическая модель термического окисления тонких монослоев кремния, учитывающая рост напряжений в переходном слое оксид - подложка по мере накопления в нем кислорода.

DOI: 10.21883/JTF.2019.04.47323.165-18

\section{Введение}

Кремний является наиболее используемым элементом при изготовлении интегральных схем электронных приборов. Согласно современным требованиям микроэлектроники, толщина оксида кремния должна составлять $\sim 10 \mathrm{~nm}$. При создании изолирующего, однородного по толщине слоя $\mathrm{SiO}_{2}$ на кремниевых подложках в структурах микроэлектроники необходимо знание оптимальных технологических параметров. Для процесса термического окисления, такими параметрами являются давление и температура в камере реактора микроэлектроники. Создание модели, начального термического окисления кремния может помочь в определении указанных параметров технологического процесса.

В силу того что процесс начального окисления кремния может зависеть от структуры поверхности, будем рассматривать поверхность $\mathrm{Si}(100)$. Указанная поверхность, соответствующая минимуму энергии, имеет димерную структуру $2 \times 1$ [1]. Процесс окисления начинается с адсорбции кислорода поверхностью кремния. Адсорбция на чистую поверхность $\mathrm{Si}(100)$ происходит без барьера [1]. Накопление кислорода на поверхности приводит к диссоциации димерных связей [2,3], что, по-видимому, обусловлено ростом напряжений в первом монослое кремния по мере накопления кислорода между димерными рядами.

В работе [4] методом радиоактивного маркера $\left({ }^{18} \mathrm{O}\right)$ установлено, что в процессе окисления кремния не происходит обмена кислородом между оксидом и диффундирующими молекулами. Из чего сделан вывод, что кислород через слой $\mathrm{SiO}_{2}$ диффундирует к границе раздела $\mathrm{SiO}_{2} / \mathrm{Si}$ в виде молекул. В [5] исследовался рост оксидных пленок разной толщины при поочередной подаче изотопов кислорода. Установлено, что для пленок, толщиной более $15 \AA$, наличие изотопа кислорода $\left({ }^{18} \mathrm{O}\right)$ наблюдается только непосредственно вблизи границы раздела оксид-подложка. Что также свидетельствует о молекулярной диффузии кислорода через оксид к границе раздела. Однако исследование оксидных пленок, толщиной менее $15 \AA$, показало наличие смешанного изотопического распределения кислорода в пленке, демонстрирующего тот факт, что процесс окисления захватывает несколько монослоев.

Значения величины энергии активации диффузии молекул $\mathrm{O}_{2}$ при окислении кремния были получены в работе [6]. В диоксиде кремния эта энергия составляет $E_{D \_o x}=1.2 \mathrm{eV}$, в то время как соответствующая величина в переходном слое равна $E_{D}=2 \mathrm{eV}$. Согласно $[7,8]$, энергетический барьер взаимодействия молекулярного кислорода с $\mathrm{Si}-\mathrm{Si}$ связью составляет $\sim 0.2-0.3 \mathrm{eV}$, что гораздо ниже энергии активации диффузии, и приводит к оккупации кислородом всех свободных $\mathrm{Si}-\mathrm{Si}$ связей переходного слоя. В связи со сказанным выше наиболее важным при изучении процесса окисления кремния является исследование переходного слоя.

Изучению непосредственно переходного слоя $\mathrm{SiO}_{2} / \mathrm{Si}$ посвящено множество работ. Во многих из них обнаружено существование в переходном слое различных оксидных состояний кремния $\left(\mathrm{Si}^{1+}, \mathrm{Si}^{2+}\right.$, $\left.\mathrm{Si}^{3+}, \mathrm{Si}^{4+}\right)$. Из исследования промежуточных оксидных состояний в ультратонких оксидных пленках при окислении поверхностей $\mathrm{Si}(100), \operatorname{Si}(110)$ и $\mathrm{Si}(111)$ в [9] сделан вывод о существовании резкой границы раздела для всех ориентаций. Аналогичный вывод был сделан в [1], где наблюдалось чередование димерной структуры в переходном слое по меpe роста оксидной пленки. Однако, согласно [10], глубина границы раздела составляет $\sim 2-3$ монослоя.

В [11] при изучении окисления первых монослоев кремния обнаружено чередование концентрации слабооксидных $\left(\mathrm{Si}^{1+}+\mathrm{Si}^{2+}\right)$ и оксидоподобных $\left(\mathrm{Si}^{3+}+\mathrm{Si}^{4+}\right)$ состояний в процессе роста оксида (рис. 1). Чередование 


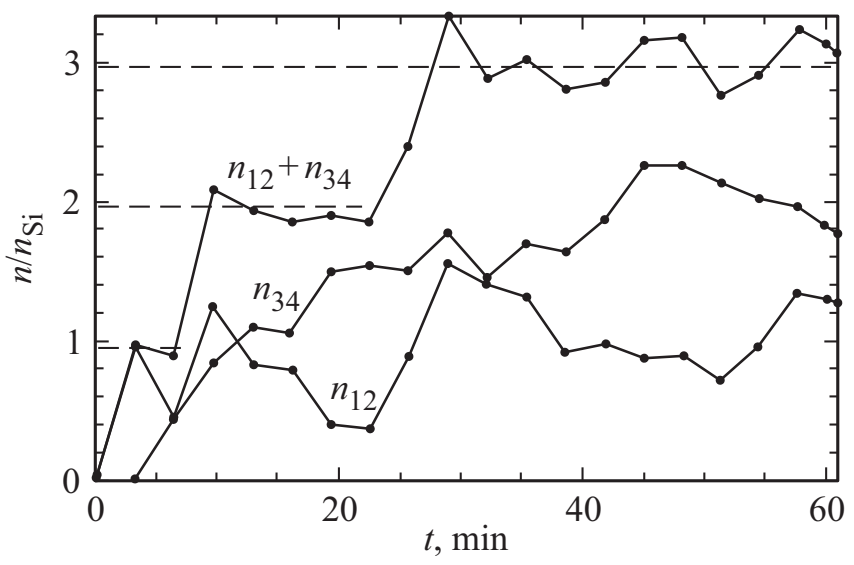

Рис. 1. Зависимость от времени концентрации оксидных состояний кремния разной степени окисления [11].

оксидных состояний кремния также было обнаружено в работе [12] при термическом окислении поверхности $\mathrm{Si}(111)$. Авторами было получено чередование промежуточных оксидных состояний $\mathrm{Si}^{1+}$ и $\mathrm{Si}^{3+}$ на границе раздела с периодом $0.7 \mathrm{~nm}$. При этом минимальная концентрация состояний $\mathrm{Si}^{1+}$ и $\mathrm{Si}^{3+}$ была $\sim 0$. Концентрация состояния $\mathrm{Si}^{2+}$ в процессе роста оксида также была $\sim 0$. Из полученного результата авторы [12] сделали вывод, что оксид растет путем образования и роста моноатомных ступеней на границе раздела. Согласно же [7], рост оксида в переходном слое осуществляется путем образования двумерных островков с последующим их ростом и слиянием на границе раздела.

В работе [13] установлено, что величина напряжения в тонких $(12-70 \mathrm{~nm})$ пленках резко растет по мере приближения к границе раздела $\mathrm{SiO}_{2} / \mathrm{Si}$, где достигает величины $\sim 2 \cdot 10^{9} \mathrm{~N} / \mathrm{m}^{2}$. В работе также получено, что значения напряжений не зависят от температуры окисления. Этот результат указывает на то, что накопление кислорода в переходном слое сопровождается ростом в нем напряжений (аналогично поверхности).

К настоящему времени предложено несколько моделей, описывающих термическое окисление кремния [6,14-16]. Так, классическая модель Дила-Гроува [6] хорошо себя зарекомендовала для пленок, толщиной более $20 \mathrm{~nm}$. Однако эта модель не учитывает возможность существования протяженного переходного слоя между растущим оксидом и подложкой кремния, а также его структуру. В [15] предложена модель окисления, согласно которой коэффициент диффузии линейно зависит от концентрации оксида кремния в переходном слое между оксидом и подложкой. Дополнительно введена релаксация со временем оксидной составляющей коэффициента диффузии переходного слоя к его значению в ненапряженном оксиде. Из сравнения расчетных кривых с экспериментом в [15] определены энергети- ческие барьеры для диффузии кислорода через оксид $(0.9 \mathrm{eV})$ и для пересечения переходного слоя $(2.17 \mathrm{eV})$, которые соответствуют результатам работы [6]. В [14] для описания процесса окисления предложена система одномерных кинетических уравнений в газовом приближении, описывающая диффузию кислорода сквозь оксид и его реакцию с образованием $\mathrm{SiO}_{2}$. В отличие от работы Дила-Гроува [6], в [14] не предполагается стационарный режим окисления. Реакция кислорода с кремнием проходит везде, где встретятся кислород c еще не провзаимодействовавшим кремнием, а не только на границе между кремнием и его оксидом. В результате граница раздела получается размытой. Такой подход должен приводить к росту ширины переходного слоя по мере роста оксидной пленки, что не подтверждается экспериментально. В модели, предложенной в [16], введена возможность продвижения кислорода к переходному слою по законам, отличным от закона Фика. Предполагается миграция легирующей примеси в твердых телах за счет дискретных скачков легирующих частиц через отдельные участки (DOCC-sites). Кроме того, предполагается зависимость вероятности реакции кислорода с кремнием от времени окисления. Сделанные предположения позволили авторам описать рост тонких пленок оксида кремния. Перечисленные выше модели не учитывают наличие напряжений в переходном слое, установленное экспериментально, присутствие различных оксидных состояний кремния в нем и изменения их концентраций в процессе окисления.

Цель настоящей работы - создание модели термического окисления тонких монослоев кремния $\mathrm{Si}(100)$, учитывающей как рост напряжений в переходном слое, так наличие и чередование различных оксидных состояний кремния в процессе окисления.

\section{Кинетика окисления}

Поскольку величина энергетического барьера внедрения кислорода в $\mathrm{Si}-\mathrm{Si}$ связь $(0.2-0.3 \mathrm{eV})$ значительно меньше энергии активации диффузии $(2 \mathrm{eV})$, то кислород, встречая на своем пути не занятую $\mathrm{Si}-\mathrm{Si}$-связь, внедряется в нее с образованием мостов вида $\mathrm{Si}-\mathrm{O}-\mathrm{Si}$. В переходном слое концентрация незанятых кислородом $\mathrm{Si}-\mathrm{Si}$-связей велика. Поэтому молекулы кислорода, достигая переходного слоя, могут занимать в нем положения как в димерных рядах с образованием $\mathrm{Si}-\mathrm{O}-\mathrm{Si}-$ мостов, лежащих в плоскости монослоя (энергия активации $E_{d}$ ), так и между атомами кремния, связывающими подложку с оксидом (энергия активации $E_{o x}$ ). Энергия активации диффузии кислорода в переходном слое составляет $\sim 2 \mathrm{eV}$ [6], что не только значительно превышает соответствующее значение в оксиде, но и фактически ограничивает проникновение кислорода в подложку кремния. Даже при температуре плавления кремния вероятность прыжка 
кислорода в оксиде кремния на три порядка превосходит значение соответствующей величины в переходном слое.

Параметр решетки в кристаллической фазе $\mathrm{SiO}_{2}$ почти в два раза превышает параметр решетки в кремниевой подложке. Следовательно, образование мостов $\mathrm{Si}-\mathrm{O}-\mathrm{Si}$ (в результате внедрения кислорода в $\mathrm{Si}-\mathrm{Si}$-связь) приводит к появлению растягивающих напряжений. Как было указано во введении, напряжения в оксидной пленке резко растут по направлению к границе раздела $\mathrm{SiO}_{2} / \mathrm{Si}$, где достигают максимальной величины [13]. Естественно предположить, что, когда величина напряжения, а следовательно, и концентрация кислорода в переходном слое достигает критического значения, происходит множественный разрыв связей, приводящий к снижению напряжения в переходном слое. Поскольку накопление кислорода на различных участках переходного слоя носит случайный характер, то разрыв связей с образованием оксидоподобных состояний осуществляется только в тех локальных областях переходного слоя, в которых критическое значение напряжения достигнуто (будем называть эту локальную область островком). Поскольку появление островков резко облегчает проникновение кислорода в подложку, то под образовавшимися $2 D$-островками возникают новые участки переходного слоя. Зарождение и последующая коалесценция островков $\mathrm{SiO}_{2}$ приводят к образованию монослоя аморфного оксида. Но поскольку диффузия через островки многократно превышает диффузию через области переходного слоя, то в области под островком накопление кислорода начнется еще до полного образования монослоя $\mathrm{SiO}_{2}$. Именно этот эффект приводит к принципиальной невозможности получения диоксида кремния толщиной строго в один монослой.

Найдем вероятность разрыва $N_{v}$ связей $\mathrm{Si}-\mathrm{Si}$ в зависимости от концентрации кислорода в переходном слое. Рассмотрим бесконечный кристалл, в котором в верхней части полупространства расположен оксид кремния, а в нижней - кремний. Между ними находится переходный слой. Будем полагать, что по мере внедрения кислорода в $\mathrm{Si}-\mathrm{Si}$-связь напряжения в переходном слое растут, а изменения объема кристалла при этом не происходит. В таком случае для статистического описания равновесной концентрации разорванных связей можно воспользоваться свободной энергией Гиббса

$$
\Phi=\Phi_{0}+E-T S+P V .
$$

Здесь $\Phi_{0}$ - часть свободной энергии, не связанная с наличием оборванных $\mathrm{Si}-\mathrm{Si}$-связей; $E=\varepsilon_{v} N_{v}$, $\varepsilon_{v}$ - энергия, необходимая для разрыва $\mathrm{Si}-\mathrm{Si}-$ связи; $S=k_{B} \ln \frac{N !}{N_{v} !\left(N-N_{v}\right) !}-$ энтропия, связанная с вероятностью разрыва $N_{v} \mathrm{Si}-\mathrm{Si}$-связей из $N$ возможных в переходном слое; $k_{B}-$ постоянная Больцмана;
$P=\sigma \frac{n_{0}}{n_{\mathrm{Si}}} \frac{N}{V}\left(1-N_{v} / N\right)$ - дополнительное давление в переходном слое, вызванное внедрением кислорода в $\mathrm{Si}-\mathrm{Si}$-связи; $\sigma$ - энергия, связанная с внедрением одного атома кислорода; $V$ - объем рассматриваемой части кристалла.

Учитывая выше сказанное, варьируя величину свободной энергии по $N_{v}$ и используя формулу Стирлинга, получим выражение для приведенного числа разорванных связей кремния в зависимости от концентрации кислорода в переходном слое

$$
\gamma=\frac{N_{v}}{N}=\left(1+\exp \left(\frac{\varepsilon_{v}-\sigma n_{0} / n_{\mathrm{Si}}}{k_{B} T}\right)\right)^{-1} .
$$

Как видно из выражения (2), число оборванных связей имеет вид размытой функции Хэвисайда. Отсюда следует резкий рост числа разорванных связей кремния при достижении критической концентрации кислорода в переходном слое $n_{0}^{c} \sim \frac{\varepsilon_{v}-k_{B} T}{\sigma}$.

Для определения параметров модели рассмотрим вначале окисление первых монослоев. Начнем с момента, когда в некоторой локальной области пространства все узлы для химической адсорбции на поверхности кремния заняты атомами кислорода. Первый монослой кремния соединен со вторым монослоем через $\mathrm{Si}-\mathrm{Si}$-связи. Часть атомов кремния на втором монослое связаны друг с другом в виде димеров $\left(n_{\mathrm{Si} \_}^{(2)}\right)$. Атомы кислорода, продиффундировавшие в область между первым и вторым монослоями, могут занимать два различных состояния. В первом случае они связывают атомы кремния $\left(n_{\mathrm{Si} d}^{(2)}\right)$, принадлежащие второму монослою, образуя слабооксидные состояния кремния $\left(n_{12 d}^{(2)}\right)$. Во втором случае атомы кислорода внедряются в Si-Si-связь между первым и вторым монослоями кремния $\left(n_{\mathrm{Si} i}^{(2)}\right)$ (межслоевые состояния). При этом кремний, находящийся во втором монослое, примет слабооксидное состояние $\left(n_{12}^{(2)} i\right)$, а кремний, находящийся в первом монослослое, - оксидоподобное состояние $\left(n_{34}^{(1)}\right)$.

Расстояние между соседними атомами кремния в оксиде почти в два раза превышает соответствующее расстояние в кремнии. Переходный слой связывает эти две структуры. Но поскольку концентрация атомов кремния в подложке почти в два раза больше, то только примерно половина из них может быть связана $\mathrm{Si}-\mathrm{O}-\mathrm{Si}$ мостами с оксидом кремния. Для учета этого факта введем параметр $\delta$, описывающий долю мостовых состояний между оксидом и подложкой. Следует ожидать, что параметр $\delta$ близок к значению $\delta \approx 0.5$. Накопление кислорода способствует росту напряжений в переходном слое. Когда его концентрация в переходном слое достигает критического значения, происходит множественный разрыв связей, что приводит к преобразованию слабооксидных состояний $\left(n_{12 \_i}^{(2)}\right)$ в оксидоподобные $\left(n_{34}^{(2)}\right)$. 
Описание вышеизложенной модели проведем с помощью системы уравнений химических реакций, которую можно представить следующим образом:

$$
\left\{\begin{array}{l}
\dot{n}_{o x}^{(1)}=Q-v_{+} n_{o x}^{(1)}\left(1-\frac{n_{o x}^{(2)}}{n_{\mathrm{Si}}}\right)+v_{-} n_{o x}^{(2)}\left(1-\frac{n_{o x}^{(1)}}{n_{\mathrm{Si}}}\right) \\
\dot{n}_{o x}^{(2)}=v_{+} n_{o x}^{(1)}\left(1-\frac{n_{o x}^{(2)}}{n_{\mathrm{Si}}}\right)-v_{-} n_{o x}^{(2)}\left(1-\frac{n_{o x}^{(1)}}{n_{\mathrm{Si}}}\right) \\
\dot{n}_{12 \_}^{(2)}=\alpha n_{o x}^{(1)} n_{\mathrm{Si} d}^{(2)} \\
\dot{n}_{12 i}^{(2)}=\beta n_{o x}^{(1)} n_{\mathrm{Si} i}^{(2)}-\gamma^{(2)} n_{o x}^{(2)} n_{12 \_i}^{(2)} \\
\dot{n}_{34}^{(1)}=\gamma^{(2)} n_{o x}^{(2)} n_{12 i}^{(2)} \\
\dot{n}_{\mathrm{Si} d}^{(2)}=-\alpha n_{o x}^{(2)} n_{\mathrm{Si} d}^{(2)} \\
\dot{n}_{\mathrm{Si} i}^{(2)}=-\beta n_{o x}^{(2)} n_{\mathrm{Si} i}^{(2)}
\end{array}\right.
$$$$
\left\{\begin{array}{l}
n_{o x}^{(1)}=0 \\
n_{o x}^{(2)}=0 \\
n_{12 d}^{(2)}=0 \\
n_{12 i}^{(2)}=0 \\
n_{34}^{(1)}=0 \\
n_{\mathrm{Si} d}^{(2)}=\delta n_{\mathrm{Si}} \\
n_{\mathrm{Si} i}^{(2)}=(1-\delta) n_{\mathrm{Si}}
\end{array}\right.
$$

Здесь $\alpha, \beta$ и $\gamma$ - вероятности соответствующих реакций; вероятность $\gamma$ является функцией от концентрации кислорода в мостовых состояниях $\mathrm{Si}-\mathrm{O}-\mathrm{Si}$ : $\gamma^{(2)}=f\left(n_{12 \_i}^{(2)}+n_{34}^{(2)}\right) ; v_{+}, v_{-}-$частоты прыжков кислорода в переходный слой и обратно, поток кислорода $Q$ на поверхность считается постоянным и равным $Q=\frac{s P}{\sqrt{2 \pi m k T}}[17]$, где $s-$ коэффициент прилипания кислорода к поверхности.

Так как энергетический барьер для внедрения молекулярного кислорода в $\mathrm{Si}-\mathrm{Si}$-связь на порядок ниже энергии активации диффузии через переходный слой, то уменьшение концентрации кислорода за счет преодоления им переходного слоя в системе (3) не учитывалось. Кроме того, на начальном этапе рассмотрения пренебрегалось диффузией кислорода через вновь образованные кластеры оксидоподобных состояний. Следует отметить, что диффузия представляет собой процесс, усредненный по значительному количеству прыжков. Но поскольку здесь рассматривается окисление небольшого числа монослоев, то данное усреднение может оказаться неправомерным. В силу этого в системе (3) межслойное движение кислорода описывается прыжками атомов с энергией активации, соответствующей диффузии.

Система уравнений (3) решалась численно. При проведении расчетов все концентрации нормировались на концентрацию атомов кремния в подложке $n_{\mathrm{Si}}$. В таблице приведены значения величин, использованные при численном решении системы (3).

На рис. 2 представлены зависимости концентраций слабооксидных и оксидоподобных состояний кремния в переходном слое от времени окисления. Сравнение с результатами работы [11] позволило определить значения величин: $\sigma=2.6 \mathrm{eV}, \quad s=5 \cdot 10^{-3}$. Из рис. 2 видно, что на начальной стадии окисления в переходном слое происходит накопление кислорода в слабооксидных $\left(n_{12}\right)$ состояниях. При достижении концентрации кислорода в этих состояниях при значении, близком к единице, происходит разрыв связей, сопровождающийся переходом слабооксидных состояний в оксидоподобные состояния $\left(n_{34}\right)$. При этом значение суммарной концентрации всех оксидных состояний остается постоянным. Когда концентрация оксидоподобных состояний кремния достигнет значения $\sim 1$, сквозь образовавшийся островок начинает диффундировать кислород.
После чего рассмотренная картина окисления повторяется для следующего монослоя.

На рис. 3 показаны поведения концентраций оксидных состояний от времени окисления при вариации параметра $\delta=0.5 \pm 0.05$. Из рисунка видно, что вариация параметра $\delta$ влияет не только на момент начала перехода слабооксидных состояний в оксидоподобные (что также определяется величиной критического напряжения $\delta$ ), но также приводит и к смене характера поведения кривых. Тот факт, что концентрация кремния в $\mathrm{Si}$ примерно в 2.16 раза превышает концентрацию атомов кремния в $\mathrm{SiO}_{2}$, а также сравнение кривых (рис. 3) с [11], указывает на то, что значение $\delta \simeq 0.5$.

Рассмотрим процесс возникновения островков оксидоподобных состояний на границе раздела. В качестве начального условия будем исследовать три слоя: верхний $\mathrm{Si}_{34}$ (все атомы кремния имеют связи с кислородом), нижний $\mathrm{Si}$ (ни один из атомов кремния не имеет связей с кислородом) и средний $\mathrm{Si}_{12}$ (атомы кремния соединены через кислород с верхним монослоем и $\mathrm{Si}-\mathrm{Si}-$ связью с нижним монослоем). Кислород, диффундируя через монослой $\mathrm{Si}_{34}$ с энергией активации прыжка $\sim 1.2 \mathrm{eV}$, попадает в область между слоями $\mathrm{Si}_{34}$ и $\mathrm{Si}_{12}$. Затем с

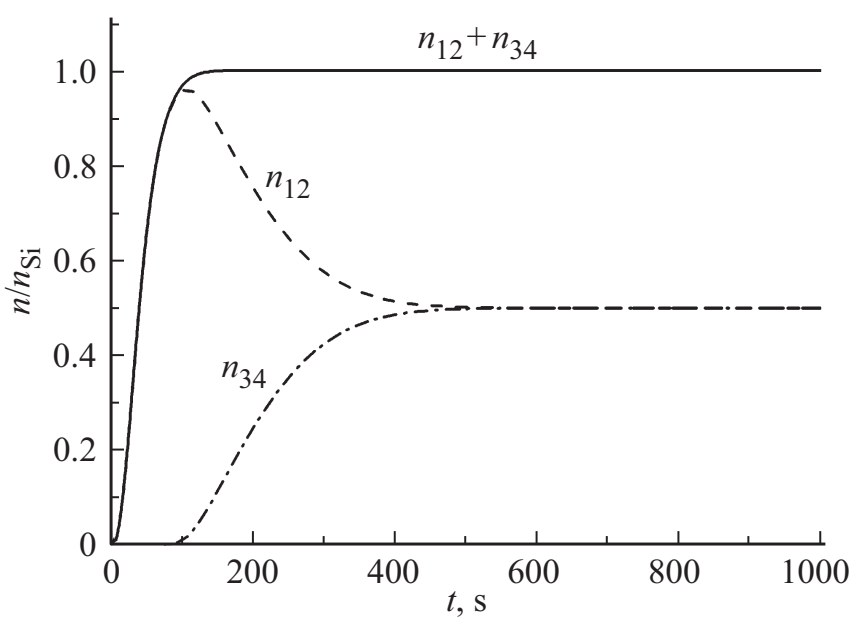

Рис. 2. Зависимость концентрации слабооксидных $n_{12}$, оксидоподобных $n_{34}$ состояний кремния и суммарной концентрации от времени окисления $(\delta=0.5)$. 

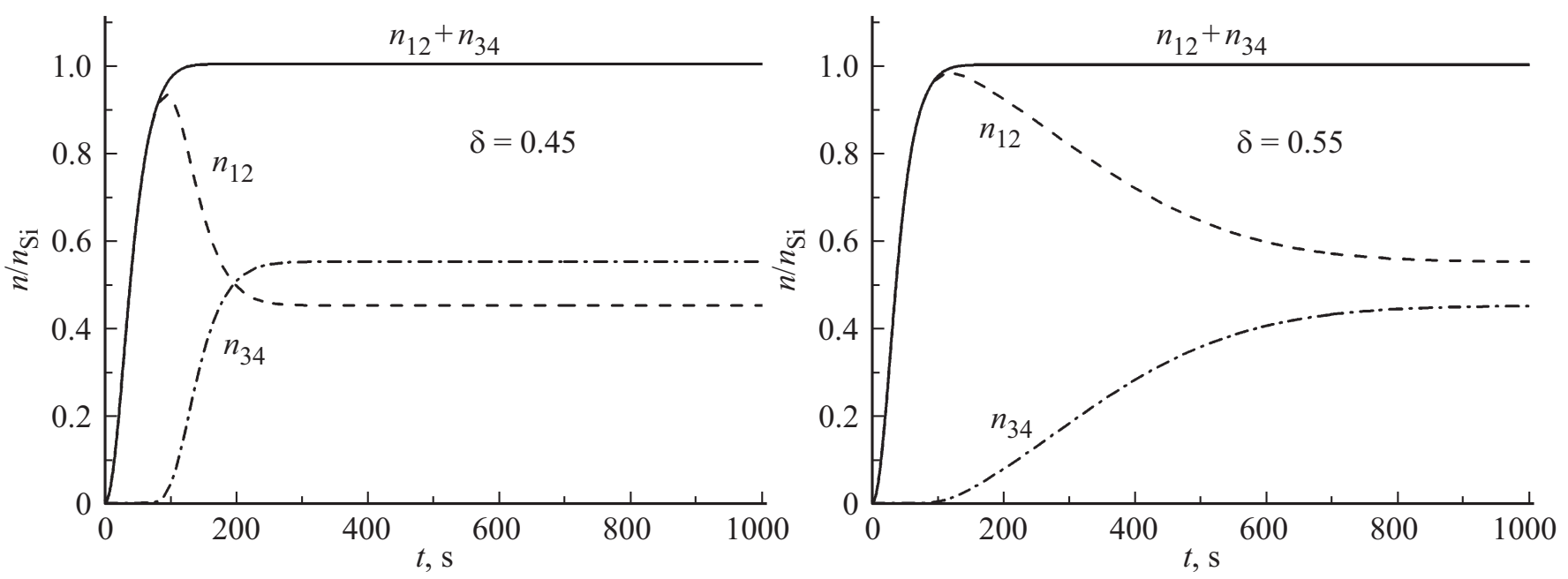

Рис. 3. Зависимость концентрации слабооксидных $n_{12}$, оксидоподобных $n_{34}$ состояний кремния и суммарной концентрации от времени окисления при различных параметрах $\delta$.

Значение величин, использованных при численных расчетах

\begin{tabular}{|c|c|}
\hline Параметр & Значение \\
\hline $\begin{array}{l}\text { Энергия, необходимая для разрыва } \\
\mathrm{Si}-\mathrm{Si} \text {-связей при образовании } \mathrm{SiO}_{2}\end{array}$ & $\varepsilon_{v}=1.82 \mathrm{eV}[6]$ \\
\hline $\begin{array}{l}\text { Энергия внедрения кислорода } \\
\text { в димерную } \mathrm{Si}-\mathrm{Si}-\text { связь }\end{array}$ & $E_{\alpha}=0.2 \mathrm{eV}[8,18]$ \\
\hline $\begin{array}{l}\text { Энергия внедрения кислорода } \\
\text { в межслоевую } \mathrm{Si}-\mathrm{Si}-\text { связь }\end{array}$ & $E_{\beta}=0.3 \mathrm{eV}[8,18]$ \\
\hline $\begin{array}{l}\text { Энергия активации диффузии кислорода } \\
\text { через переходный слой }\end{array}$ & $E_{d}=2.1 \mathrm{eV}[6]$ \\
\hline Давление кислорода в газовой фазе & $P=10^{-6}$ Topp $[11]$ \\
\hline Температура процесса окисления & $T=1135 \mathrm{~K}[11]$ \\
\hline
\end{tabular}

энергией активации $\sim 2 \mathrm{eV}$ попадает в область между слоями $\mathrm{Si}_{12}$ и $\mathrm{Si}$, где внедряется в $\mathrm{Si}-\mathrm{Si}-$ связь с энергией $\sim 0.2 \mathrm{eV}$. В результате на среднем монослое появляются состояния $\mathrm{Si}_{34}$, которые в результате слияний образуют островки. Появление островков способствует росту напряжений на их границе, что увеличивает латеральную диффузию и захват кислорода границей островков. Указанное предположение согласуется с работой [7], где рост оксида в переходном слое осуществляется путем образования двумерных островков с последующим их ростом и слиянием. В [7] также указано, что диффузия кислорода параллельно монослоям происходит при температуре выше некоторой критической. При этих температурах уже возможна миграция атомов кислорода вглубь подложки. Однако дальнейшее продвижение килорода вглубь подложки не происходит, поскольку вероятность скачка кислорода из подложки в сторону переходного слоя значительно больше, нежели в подложку.
Проведенное моделирование ухода кислорода через переходный слой (с энергией активации $\sim 1.2 \mathrm{eV}$ ) путем введения в уравнение (2) системы (3) слагаемого, описывающего уход, показало, что соответствие с кривыми окисления работы [11] достигается при величине концентрации $n_{34} \sim 0.9$. Полученный результат объясняется резким увеличением латеральной диффузии кислорода к границам образовавшихся островков за счет роста напряжений в переходном слое. В итоге глубина границы раздела составит $\sim 2-3$ монослоя, что согласуется с работой [10].

Исследуем процесс окисления глубоких слоев кремния (ось $z$ направим от поверхности в сторону подложки кремния). Рассмотрим ситуацию, когда в некоторой локальной области пространства $k-2$ верхних монослоя таковы, что все атомы кремния в них имеют по четыре связи с кислородом. $k-1$ монослой кремния соединен с $k-2$-м монослоем через мостовые связи $\mathrm{Si}-\mathrm{O}-\mathrm{Si}$ и с $k$-м монослоем кремния через $\mathrm{Si}-\mathrm{Si}-$ связи. Как и в случае начального окисления, будем полагать, что некоторое количество атомов кремния на $k$-м монослое (доля $\delta$ ) связаны друг с другом в виде димеров $\left(n_{\mathrm{Si} d}^{(k)}\right)$. Атомы кислорода, продиффундировавшие в область между $k$-м и $k-1$-м монослоями, могут занимать два различных состояния. В первом случае они связывают атомы кремния $\left(n_{\mathrm{Si} \_}^{(k)}\right)$, принадлежащие $k$-му монослою, образуя слабооксидные состояния кремния $\left(n_{12}^{(k)} d\right)$. Во втором случае атомы кислорода внедряются в $\mathrm{Si}-\mathrm{Si}$-связь между $k$-м и $k-1$-м монослоями кремния $\left(n_{\mathrm{Si} i}^{(k)}\right)$ (межслоевые состояния). При внедрении кислорода кремний, находящийся в $k$-м монослое, находится в слабооксидном состоянии $\left(n_{12}^{(k)}\right)$, а кремний, находящийся в $k-1$-м монослое, занимает оксидоподобное состояние $\left(n_{34}^{(k-1)}\right)$. 
Соотвествующую систему кинетических уравнений можно записать в виде

$$
\left\{\begin{array}{l}
\dot{n}_{o x}^{(k-1)}=Q-v_{+} n_{o x}^{(k-1)}\left(1-\frac{n_{o x}^{(k)}}{n_{\mathrm{Si}}}\right)+v_{-} n_{o x}^{(k)}\left(1-\frac{n_{o x}^{(k-1)}}{n_{\mathrm{Si}}}\right) \\
\dot{n}_{o x}^{(k)}=v_{+} n_{o x}^{(k-1)}\left(1-\frac{n_{o x}^{(k)}}{n_{\mathrm{Si}}}\right)-v_{-} n_{o x}^{(k)}\left(1-\frac{n_{o x}^{(k-1)}}{n_{\mathrm{Si}}}\right) \\
\dot{n}_{12 \_}^{(k)}=\alpha n_{o x}^{(k)} n_{\mathrm{Si} d}^{(k)} \\
\dot{n}_{12 \_i}^{(k)}=\beta n_{o x}^{(k)} n_{\mathrm{Si} i}^{(k)}-\gamma^{(k)} n_{o x}^{(k)} n_{12 \_i}^{(k)} \\
\dot{n}_{34}^{(k-1)}=\gamma^{(k)} n_{o x}^{(k)} n_{12 \_i}^{(k)} \\
\dot{n}_{\mathrm{Si} d}^{(k)}=-\alpha n_{o x}^{(k)} n_{\mathrm{Si} d}^{(k)} \\
\dot{n}_{\mathrm{Si} \_i}^{(k)}=-\beta n_{o x}^{(k)} n_{\mathrm{Si} i}^{(k)} i
\end{array}\right.
$$$$
\left\{\begin{array}{l}
n_{o x}^{(k-1)}=0 \\
n_{o x}^{(k)}=0 \\
n_{12 \_d}^{(k)}=0 \\
n_{12 \_i}^{(k)}=0 \\
n_{34}^{(k-1)}=0 \\
n_{\mathrm{Si} i d}^{(k)}=\delta n_{\mathrm{Si}} \\
n_{\mathrm{Si} \_i}^{(k)}=(1-\delta) n_{\mathrm{Si}}
\end{array}\right.
$$

Таким образом, система (4) полностью аналогична системе (3), описывающей окисление второго монослоя, с той лишь разницей, что поток кислорода $Q$ на границу переходного слоя теперь определяется диффузией кислорода сквозь оксид.

Уравнение диффузии кислорода сквозь оксид можно описать вторым законом Фика:

$$
\frac{\partial n}{\partial t}=D \frac{\partial^{2} n}{\partial z^{2}}
$$

В стационарном режиме можно полагать, что концентрация кислорода на поверхности $\left(n_{0}\right)$ постоянна, а поскольку переходный слой является стоком для продиффундирующего кислорода, положим его концентрацию при решении уравнения (5) в переходном слое, расположенном на глубине $H$, равной нулю:

$$
\left\{\begin{array}{l}
n(z=0, t)=n_{0} \\
n(z=H, t)=0 \\
n(z, t=0)=0
\end{array} .\right.
$$

Решение уравнения диффузии (5) с граничными условиями (6) имеет вид

$$
n(z, t)=n_{0} \frac{H-z}{H}-\frac{2 n_{0}}{\pi} \sum_{k=1}^{\infty} e^{-\frac{\pi^{2} k^{2} D t}{H^{2}}} \sin \left(\frac{\pi k z}{H}\right) .
$$

Откуда следует выражение для плотности потока частиц на границу переходного слоя

$J(H, t)=-\left.D \frac{\partial n}{\partial z}\right|_{z=H}=\frac{D n_{0}}{H}\left(1+2 \sum_{k=1}^{\infty} e^{-\frac{\pi^{2} k^{2} D t}{H^{2}}} k \cos (\pi k)\right)$.

Предположим, что сумма, стоящая в (8), много меньше единицы. Тогда, пренебрегая ее вкладом, поток частиц на $(k-1)$-й монослой определяется выражением

$$
Q=\frac{D n_{0}}{H}
$$

Система (4) с нормированным на $n_{\mathrm{Si}}$ потоком кислорода (9), для $k$-ого монослоя, была решена численно. Как и следовало ожидать, процесс окисления переходного слоя аналогичен окислению поверхностных слоев кремния (рис. 2). Отличие состоит в том, что процесс окисления растягивается во времени, что обусловлено уменьшением скорости доставки кислорода на границу переходного слоя.

Получим зависимость толщины выращенной оксидной пленки от времени окисления. Полагая, что диффундирующий через оксид кислород не может преодолеть переходный слой, определим число частиц в нем

$$
\Delta N=J(H, t) \Delta S \Delta t=n_{o x} \Delta S a,
$$

где $n_{o x}$ - концентрации кислорода в оксиде, а $a-$ ширина переходного слоя. Переходя к пределу бесконечно тонкого переходного слоя, получим уравнение для зависимости толщины оксида от времени окисления

$$
n_{o x} \dot{H}=J(H, t)
$$

Решим уравнение (11) методом последовательных приближений. Предположим, что слагаемое, содержащее знак суммы в (8), мало. Тогда, интегрируя уравнение (11), получим известную параболическую зависимость [6] глубины оксида от времени окисления

$$
H=\sqrt{\frac{2 D n_{0} t}{n_{o x}}} .
$$

Подставляя полученное выражение в поток (8), найдем поправку к зависимости глубины оксида (12) от времени

$$
H=\sqrt{\frac{2 t D n_{0}}{n_{o x}}\left(1+2 \sum_{k=1}^{\infty} e^{\left.-\frac{\pi^{2} k^{2} n_{o x}}{2 n_{0}} k \cos (\pi k)\right)}\right.}
$$

Значение суммы в скобках формулы (13) при $n_{o x}=n_{0}$ равно 0.014, что подтверждает сделанное предположение о ее малости. Поскольку экспериментальное значение коэффициента диффузии определяется с погрешностью порядка $10 \%$, то очевидно, что для расчетов достаточно использовать выражение (12). Тем не менее поскольку процесс окисления осуществляется не во всем монослое, а в локальной его области, то переходный слой содержит несколько монослоев. 


\section{Заключение}

Предложена модель термического окисления первых монослоев кремния $\mathrm{Si}(100)$, учитывающая наличие различных оксидных состояний кремния в переходном слое. Учтено, что накопление кислорода в переходном слое приводит к разрыву $\mathrm{Si}-\mathrm{Si}$-связей. Поскольку накопления кислорода в переходном слое носит случайный характер, то рост оксида начинается с образования в переходном слое двумерных островков оксидоподобных состояний. Под островками еще до их коалесценции (когда концентрация оксидоподобных состояний превысит критическое значение $\sim 0.9$ монослоя) образуется область переходного слоя, поскольку энергия активации прыжков кислорода сквозь островок почти в два раза меньше соответствующего значения в переходном слое. По той же причине рост оксида происходит путем продвижения переходного слоя толщиной в 2-3 монослоя вглубь подложки кремния.

Сравнение расчетного поведения кинетики окисления первых монослоев кремния с результатами эксперимента [11] позволило определить величину свободного параметра $\sigma=2.6 \mathrm{eV}$, связанного с появлением кислорода в мостах $\mathrm{Si}-\mathrm{O}-\mathrm{Si}$, и оценить долю димерных связей в переходном слое: $\delta \cong 0.5$.

Исследование окисления глубоких монослоев кремния привело к известной параболической зависимости [6] глубины окисления от времени. Показано, что поправка, полученная при решении уравнения диффузии, существенно меньше точности эксперимента и потому может не учитываться.

Работа выполнена в рамках Государственного задания ФТИАН им. К.А. Валиева РАН Минобрнауки РФ по теме № 0066-2019-0004.

\section{Список литературы}

[1] Watanabe H., Kato K., Uda T., Fujita K., Ichikawa M. // Phys. Rev. Lett. 1998. Vol. 80. N 2. P. 345-348.

[2] Green M.L., Gusev E.P., Degraeve R., Garfunkel E.L. // J. Appl. Phys. 2001. Vol. 90. N 5. P. 2057-2121.

[3] Bongiorno A., Pasquarello A. // J. Mater. Sci. 2005. Vol. 40. P. 3047-3050.

[4] Lu H.C., Gustafsson T., Gusev E.P., Garfunkel E. // Appl. Phys. Lett. 1995. Vol. 67. P. 1742-1744.

[5] Gusev E.P., Lu H.C., Gustafsson T., Garfunkel E. // Mat. Res. Soc. Symp. Proc. 1994. Vol. 318. P. 69-74.

[6] Deal B.E., Grove A.S. // J. Appl. Phys. 1965. Vol. 36. N 12. P. 3770-3778.

[7] Tsetseris L., Pantelides S. T. // PRL. 2006. Vol. 97. P. 116101.

[8] Akiyama T., Kageshima H. // Surf. Sci. 2005. Vol. 576. P. L65-L70.

[9] Hattori T., Suzuki T. // Appl. Phys. Lett. 1983. Vol. 43. N 5. P. 470-472.

[10] Himpsel F.G., Mc Feely F.R., Taleb-Ibrahimi A., Yarmoff J.A., Hollinger G. // Phys. Rev. B. 1998. Vol. 38. N 9. P. 6084-6096.
[11] Borman V.D., Gusev E.P., Lebedinskii Yu.Yu., Troyan V.I. // Phys. Rev. Lett. 1991. Vol. 67. N 17. P. 2387-2390.

[12] Ohishy K., Hattoty T. // Jpn. J. Appl. Phys. 1994. Vol. 33. P. L675-1678.

[13] Szekeres A. // NATO Sci. Series 3 High Technol. 1998. Vol. 47. P. 65-73.

[14] Almadia R.M.C., Goncalves S., Baumvol I.J.R. // Phys. Rev. B. 2000. Vol. 61. N 19. P. 12992-12999.

[15] Александров О.В., Дусь А.И. // ФТП. 2008. Т. 42. Вып. 11. C. $1400-1406$.

[16] Gerlach G., Maser K. // Adv. Cond. Matt. Phys. 2016. Vol. 2016. P. 1-13.

[17] Ландау Л.Д., Лифииц Е.М. Теоретическая физика. Статистическая физика. М.: Наука, 1998. С. 567.

[18] Kageshima H., Shiraishi K. // Phys. Rev. Lett. 1998. Vol. 81. N 26. P. 5936-5939. 